\title{
Dissecting Molecular Events in Thyroid Neoplasia Provides Evidence for Distinct Evolution of Follicular Thyroid Adenoma and Carcinoma
}

Kerstin Krause, ${ }^{*}$ Susanne Prawitt, ${ }^{*}$ Markus Eszlinger, ${ }^{*}$ Christian Ihling, ${ }^{\dagger}$ Andrea Sinz, ${ }^{\dagger}$ Katrin Schierle, ${ }^{\ddagger}$ Oliver Gimm, ${ }^{\S}$ Henning Dralle, ${ }^{\S}$ Frank Steinert, " Sien-Yi Sheu, Kurt W. Schmid," and Dagmar Fuhrer**

From the Clinic for Endocrinology and Nephrology* and the Institute of Pathology, ${ }^{\ddagger}$ University of Leipzig, Leipzig; the Department of Pharmaceutical Chemistry and Bioanalytics, ${ }^{\dagger}$ Institute of Pharmacy, and the Department of General, Visceral, and Vascular Surgery, ${ }^{\S}$ Martin Luther University of HalleWittenberg, Halle-Wittenberg; the Centre for Minimally Invasive

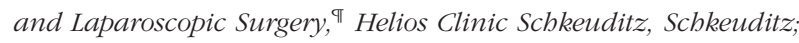
and the Institute of Pathology and Neuropathology" and the Clinic for Endocrinology, ${ }^{* *}$ University of Duisburg-Essen, Essen, Germany

Benign hypofunctional cold thyroid nodules (CTNs) are a frequent scintiscan finding and need to be distinguished from thyroid carcinomas. The origin of CTNs with follicular morphologic features is unresolved. The DNA damage response might act as a physiologic barrier, inhibiting the progression of preneoplastic lesions to neoplasia. We investigated the following in hypofunctional follicular adenoma (FA) and follicular thyroid cancer (FTC): i) the mutation rate of frequently activated oncogenes, ii) the activation of DNA damage response checkpoints, and iii) the differential proteomic pattern between $F A$ and FTC. Both FTC and FA, which did not harbor RAS, phosphoinositide-3-kinase, or $\mathrm{PAX} /$ peroxisome proliferator activated receptor- $\gamma$ mutations, express various proteins in common and others that are more distinctly expressed in FTC rather than in FA or normal thyroid tissue. This finding is in line with the finding of constitutive DNA damage checkpoint activation (p-Chk2, $\gamma$-H2AX) and evidence for replicative stress causing genomic instability (increased cyclin $\mathrm{E}$, retinoblastoma, or E2F1 mRNA expression) in FTC but not FA. We discuss the findings of the increased expression of translationally controlled tumor protein, phosphatase $2 \mathrm{~A}$ inhibitor, and DJ-1 in FTC compared with FA identified by proteomics and their potential implication in follicular thyroid carcinogenesis. Our present findings argue for the definition of FA as a truly benign entity and against progressive development of FA to FTC. (Am J Pathol 2011, 179:3066-3074; DOI: 10.1016/j.ajpath.2011.08.033)

Currently, it is not known whether hypofunctional cold thyroid nodules (CTNs) represent truly benign thyroid neoplasia or thyroid lesions with an inherent malignancy potential. In particular, for CTNs with follicular morphologic features, follicular adenoma (FA) needs to be distinguished from follicular thyroid cancer (FTC) or follicular variant of papillary thyroid carcinoma. To date, several studies propose using the expression of certain genes or proteins to discriminate between benign and malignant follicular lesions, with the aim of applying them as prediagnostic markers. Galectin-3 was originally a promising marker to predict malignancy, but its practical value is diminished by high false-positive results. ${ }^{1-3}$

Tumor-suppressive features conceal the selective advantage that an oncogenic mutation would induce. Two recent studies have independently demonstrated the existence of tumorigenesis barriers that slow or inhibit the progression of preneoplastic lesions to neoplasia. Thus, common human cancers (eg, lung, breast, and colon carcinoma) evolve in a multistep process whereby characteristic molecular alterations are already apparent in the earliest noncancerous lesions and accumulate during cell transformation. ${ }^{4,5}$ These genetic alterations include aberrant promotion of S-phase entry through oncogenic stress and replicative stress (ie, induction of DNA strand breaks), which, if accompanied by errors in DNA repair,

Supported by the Deutsche Forschungsgemeinschaft (Fu 356/3-1 to D.F.).

Accepted for publication August 26, 2011.

Supplemental material for this manuscript can be found at http://ajp. amjpathol.org or at doi: 10.1016/j.ajpath.2011.08.033.

Address reprint requests to Dagmar Fuhrer, M.D., Ph.D., University of Duisburg-Essen, Clinic of Endocrinology, Hufelandstraße 55, D-45147 Essen, Germany. E-mail address: dagmar.fuhrer@uk-essen.de. 
progressively leads to genomic instability. As a consequence, DNA damage response (DDR) genes (ATM, Chk2, H2AX) and functional checkpoints (p53, 53BP1) are activated. ${ }^{4-7}$

In this study, we investigated the cause of CTNs with follicular morphologic features. Thus, we screened FA and FTC for i) common oncogenic mutations, ii) constitutive DDR activation and replicative stress, and iii) differences in global protein expression between FA and FTC with the working hypothesis that these findings would argue for a progression model or suggest a separate pathogenic evolution of FA and FTC. Thus, if FA is made up of premalignant lesions, then exclusion of malignancy (by, for example, improved diagnostics of fineneedle aspiration biopsies) will need to be revised.

\section{Materials and Methods}

\section{Thyroid Samples}

For proteome analysis and Western blotting, 10 solitary CTNs (all FAs), 10 surrounding normal thyroid (NT) tissues of the same patient, and seven FTCs (three welldifferentiated FTCs and four poorly differentiated FTCs) were studied. For immunohistochemistry an independent sample set consisting of 46 FAs and 46 FTCs (31 minimally invasive and 15 widely invasive) was used (triplicates per sample). Thyroid nodules were identified by ultrasonography. The corresponding scintiscan result of a hypofunctioning nodule and intraoperative inspection confirmed the presence of a solitary thyroid lesion. Immediately after surgical removal, the native tissue was inspected by the pathologist, and tissue sections were shock-frozen in liquid nitrogen and prepared for histologic analysis. Classification of the thyroid nodules was performed by the pathologist according to World Health Organization criteria. The term FA was used for benign follicular lesions that were completely encapsulated. The term FTC was used if capsule invasion and/or vascular invasion was present. Poorly differentiated FTCs refer to lesions with solid, trabecular, insular, and/or scirrhous growth and foci of necrosis and/or convoluted nuclei. ${ }^{8}$ The macroscopically normal surrounding thyroid tissue was investigated histologically and showed NT morphologic features in all patients. (Clinical patient data are listed in Supplemental Table S1 at http://ajp.amjpathol. org). All patients gave informed consent, and the study was approved by the local ethics committee.

\section{RNA Extraction and Quantitative Real-Time PCR}

Snap-frozen tissue samples were pulverized and transferred into TRIzol reagent (Invitrogen, Carlsbad, CA). RNA extraction and cDNA synthesis were performed as previously described, and expression of the housekeeping gene $\beta$-actin (ACTB) was demonstrated in all samples by real-time PCR. ${ }^{9}$ Real-time PCR (LightCycler System, LightCycler-DNA Master SYBR Green I Kit; Roche, Mannheim, Germany) was performed using intron spanning primers for CCNE, E2F1, and RB1 and the housekeeping gene ACTB. Primer sequences and PCR conditions are available on request.

\section{Mutational Screening and Sequencing Analysis}

For detection of RAS point mutations, codons 12/13 and 61 of exons 1 and 2, respectively, of the $\mathrm{H}_{-}, \mathrm{N}-$, and K-RAS oncogenes were screened as previously described. ${ }^{10}$ Mutational analysis of the PIK3CA gene was performed in exon 9 (helical domain) and exon 20 (kinase domain) using the primers and PCR conditions reported by Garcia-Rostan et al. ${ }^{11}$ Detection of the PAX and peroxisome proliferator activated receptor (PPAR)- $\gamma$ fusion gene (PAX/PPAR $\gamma$ ) was performed as previously described. ${ }^{12}$ Polyethylene glycol-purified PCR products were sequenced using BigDye terminator sequencing chemistry (Applied Biosystems, Carlsbad, CA), and sequence analysis was performed on the Genetic Analyzer ABI 377 (Applied Biosystems) as previously described. ${ }^{13}$ Positive controls were cDNA from plasmids carrying the H1047R (provided by Dr. Bert Vogelstein, Johns Hopkins University Medical Institutions, Baltimore, MD) and the PAX8/PPAR $y$ rearrangement (provided by Dr. Todd Kroll, University of Chicago Medical Center, Chicago, IL). ${ }^{14}$ The H-RASV12 mutation was generated in human cDNA (from NT tissue) using the Stratagene Quick-Change site-directed mutagenesis kit according to the manufacture's description and the following primers: RASV12F 5'-AAGCTGGTGGTGGTGGGCGCCGTCGGTGTGGGCAA-3' and RASV12R 5'TTGCCCACACCGACGGCGCCCACCACCACCAGCTT-3'.

\section{Sample Preparation, Protein Extraction, and Two-Dimensional Gel Electrophoresis}

Cytosolic protein extracts were prepared as previously described..$^{15}$ Thyroglobulin measurement was performed using the Brahms thyroglobulin RIA-Kit (BRAHMS AG, Hennigsdorf, Germany), and sample load for protein expression analysis was corrected for thyroglobulin content as previously described. ${ }^{15}$ Isoelectric focusing was performed in 24-cm-long, $\mathrm{pH} 4$ to 7 immobilized $\mathrm{pH}$ gradient (IPG) strips (GE Healthcare, Freiburg, Germany) followed by SDS-PAGE in $8 \%$ to $16 \%$ gradient gels. ${ }^{15}$ All samples were run in triplicate.

\section{Protein Detection and Spot Analysis}

After SDS-PAGE, gels were stained with Deep Purple protein stain (GE Healthcare) according to the manufacturer's description. Gels were scanned using the Typhoon 9200 laser scanner (GE Healthcare) at $100-\mu \mathrm{m}$ resolution. Gel analysis was performed using the ImageMaster Two-Dimensional Platinum 7.0 Software (GE Healthcare) to detect, normalize, and quantify protein expression. Spots displaying a 1.5 or greater averagefold change in abundance and a $P<0.05$ were selected for mass spectrometry. For spot picking, a preparative gel with a $1000-\mu \mathrm{g}$ protein load was run and stained with colloidal Coomassie blue after scanning. ${ }^{15}$ 


\section{Tryptic Digestion and Protein Identification}

The proteins were in-gel digested following standard protocols. ${ }^{16}$ The samples were analyzed using an Ultraflex III matrix-assisted laser desorption/ionization tandem timeof-flight mass spectrometer (Bruker Daltonik, Bremen, Germany). Mass spectra in the range of 740 to $500 \mathrm{~m} / \mathrm{z}$ were acquired in the positive ionization and reflectron mode by accumulating data from 2000 laser shots per sample (FlexControl 3.0; Bruker Daltonik). Signals were labeled (FlexAnalysis 3.0; Bruker Daltonik) and searched against the SwissProt database (http://www.expasy.ch) using Biotools 3.2 (Bruker Daltonik) and Mascot server 2.2 (Matrix Science Boston, MA). After processing of the fragment ion spectra, a tandem mass spectrometry (MS/MS) database search was performed (Biotools and Mascot).

\section{Principal Component Analysis}

The protein expression data matrix of the proteins showing a significant differential expression for FA, FTC, and NT of a \pm 1.5 -fold difference in protein expression and $P<0.05$ (Mann-Whitney rank sum) from the 2-dimensional gels was subjected to principal component analysis (PCA) to view the overall trend and the similarity of the different gels. The PCA allows identifying key variables in a multidimensional data set that explain the differences between the experiments in the best way. When assuming $m$ experiments, each with $n$ proteins, the aim of the PCA is to reduce the dimensionality of the data matrix by the identification of $r \leq n$ new variables. These $r$ principal components explain the variance of the original $n$ variables as well as possible while they are uncorrelated and orthogonal. This reduction of dimensionality allows an improved data visualization and analysis. The PCA was based on Pearson correlation metric and was performed by means of the Genesis software (http://genome.tugraz.at). ${ }^{17}$

\section{Immunoblotting}

Western blot analysis was performed as described previously. ${ }^{18}$ Fifty micrograms of protein, adapted to an equal thyroglobulin amount, was subjected to $10 \%$ SDSPAGE, transferred to nitrocellulose membranes, and probed with anti-TCTP antibody (Abcam, Cambridge, UK). Rabbit IgG conjugated with peroxidase was used as secondary antibody (1.0000; Cell Signaling, Charlottesville, VA) and was visualized by enhanced chemiluminescence (Pierce, Milwaukee, WI). Western blot densitometry analyses for protein quantification were performed with ImageJ software (http://rsb.info.nih.gov/ij/index.htm/).

\section{Immunohistochemistry}

Immunohistochemistry was performed as previously described. ${ }^{18}$ The following primary antibodies were used: antiphospho-Chk2 (Thr68), anti-phospho-H2AX (Ser139) (both from Cell Signaling Technology), anti-I2 protein phosphatase 2A (PP2A), and anti-DJ-1 (both from Abcam). For con- trols, tissues from colon carcinomas (for $\gamma$-H2AX and $\mathrm{p}$ Chk2), Graves' disease (for DJ-1), and breast carcinomas (for I2PP2A) were used. The immunostaining patterns were evaluated and scored as suggested by Bartkova et $\mathrm{al}^{4}$ : 1 , negative (no positive staining or up to $1 \%$ of positive cells); 2 , low (with at least $20 \%$ of the section showing $2 \%$ to $10 \%$ positive cells); 3 , moderate (with at least $20 \%$ of the section showing $11 \%-50 \%$ positive cells); and 4 , strong (with at least $20 \%$ of the section showing $51 \%$ 90\% positive cells).

\section{Results}

\section{Absence of Oncogenic Mutations in RAS and PI3KCA and Absence of PAX8/PPAR- $\gamma$ Rearrangements in Follicular Thyroid Tumors}

$\mathrm{H}-, \mathrm{K}-$, and N-RAS mutations, PAX8/PPAR $\gamma$ rearrangements, and mutations of the catalytic subunit $\mathrm{p} 110 \alpha$ of the PI3 kinase (PI3KCA) are distinct genetic alterations that can be detected to variable degrees in benign and malignant follicular thyroid tumors. Thus, we first aimed to characterize the study cohort ( $n=10 \mathrm{FAs}, n=10 \mathrm{NTS}$, $n=7$ FTCs) according to the prevalence of these oncogenic mutations.

Mutations in the three RAS genes occurred in neither FTCs nor FAs. Neither FTCs nor FAs showed mutations in the helical domain (exon 9) or the kinase domain of the PI3K (exon 20). Moreover, no PAX8/PPAR $y$ rearrangements were detected in FTCs and FAs. Furthermore, no mutations in either of the oncogenes were found in the surrounding normal tissues.

\section{Activation of DDR and Genomic Instability in FTC but Not FA}

Bartkova et $\mathrm{al}^{4}$ demonstrated that several human tumors (but not normal tissue) express markers of an activated DDR, including ATM, Chk2, phosphorylated H2AX, and p53, already in a premalignant stage. ${ }^{19}$ Thus, it is proposed, that the DDR machinery acts as an anticancer barrier, protecting cells against the progression of tumors from their early stages into malignant invasive lesions. ${ }^{4,19}$ This principle has been demonstrated for a number of human malignant neoplasms. Therefore, we asked whether similar changes are also present in follicular thyroid tumors and would suggest sequential evolution of FA to FTC.

We performed immunohistochemistry on a panel of FAs $(n=46)$ and FTCs ( $n=46$ with 31 minimally invasive and 15 widely invasive FTCs) using antibodies against activated H2AX (phosphorylated at Ser139 and $\gamma$-H2AX) and activated Chk2 (phosphorylated at Thr68). In contrast to the low staining in FA and NT, FTC showed a strong staining of $\gamma-\mathrm{H} 2 \mathrm{AX}$ (Figure 1A). A similar pattern was found when samples were stained against anti-pChk2 with negative staining in NT and FA compared with a positive staining intensity in FTC (Figure 1B). Notably, there was no difference in DDR staining when comparing minimally invasive FTC with widely invasive FTC. 
A

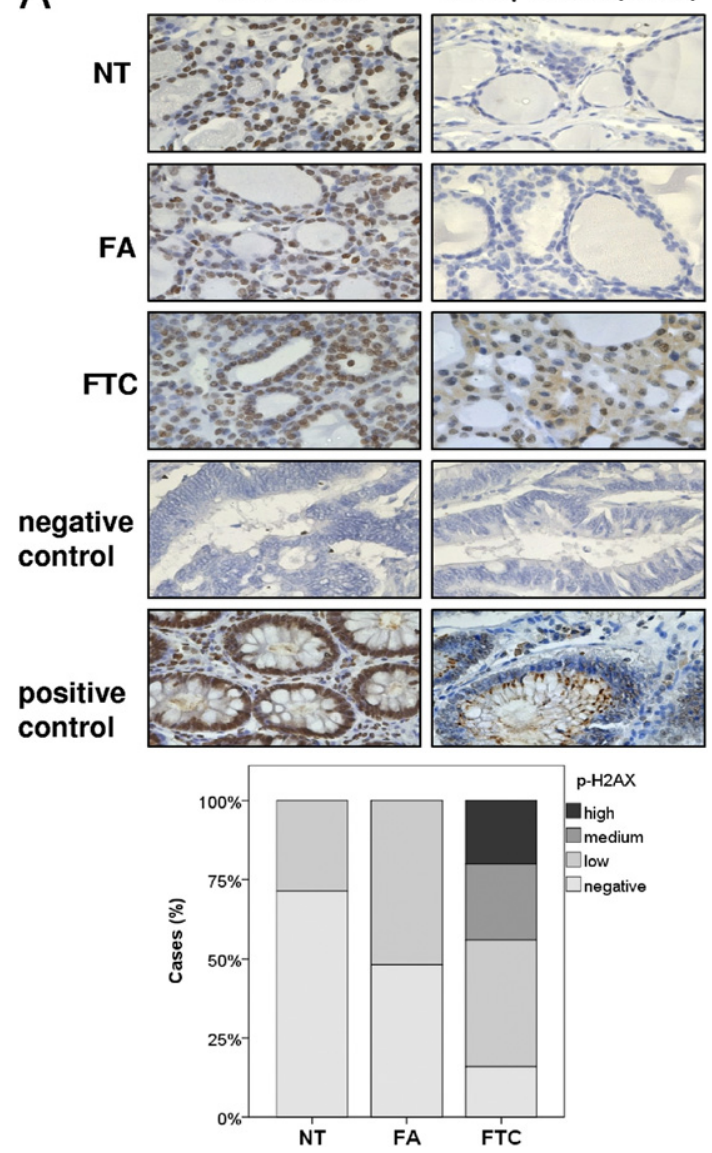

B

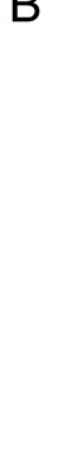

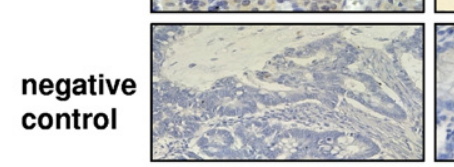

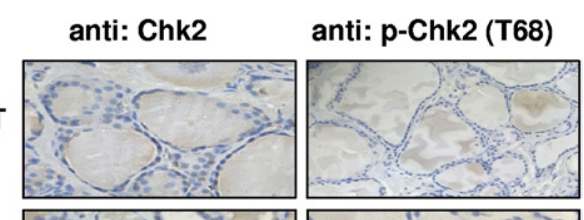

FA
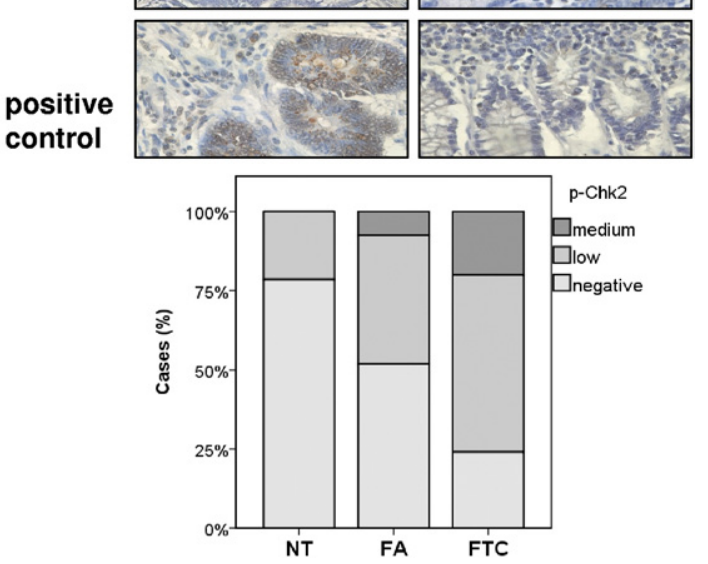

Figure 1. Constitutive activation of DDR in FTC but not in FA and NT. Immunohistochemical sections of FTC display strong staining of H2AX ( $\gamma$-H2AX) (A) and moderate staining intensity of Chk2 (T-68-Chk2) in FTC but low or complete absence of staining in FA and NT (B). Original magnification, $\times 400$.

Using pATM, we found abundant staining in FA, FTC, and NT, whereas staining for p53 was absent in all thyroid tissue samples. Furthermore, we performed quantitative real-time PCR to analyze the mRNA expression of oncogenes in the retinoblastoma $(R B)$ protein pathway $(R B$, E2F1) and cyclin E as common events found to enhance genomic instability by induction of replicative stress. We found a significant up-regulation of cyclin E, E2F1, and RB mRNA expression in FTC compared with FA $(P<$ $0.05, P<0.001$, and $P<0.006$, respectively) whereby mRNA expression levels (cyclin E, E2F1, and RB) were comparable in well-differentiated and poorly differentiated FTC. In contrast, we found no significant difference in mRNA expression of these genes between FA and NT (Figure 2).

\section{Differential Protein Expression in FA and FTC}

Transformation of a normal cell into a cancer cell is linked to altered gene regulation and protein expression. The direct comparison of thyroid cancer and thyroid tumor tissue is a feasible method to identify protein expression signatures that characterize a benign or malignant state.

We investigated FA $(n=10)$ and the adjacent NT $(n=$ $10)$, as well as FTC $(n=8)$, to identify potential biomarkers, which may place benign FA as a progressive lesion or a separate benign entity. However, the direct comparison of clinical samples is arduous because the sample heterogeneity increases the probability of false-positive results. The thyroid proteome comprises a vast intrinsic complexity that is primarily due to the varying content of thyroglobulin. ${ }^{20}$ To avoid the influence of different thyroglobulin protein contents on the protein patterns of the respective samples, we adapted the protein loads per gel to the thyroglobulin content of the sample. ${ }^{15}$ All samples that had been analyzed by genotyping were subjected to this proteomic approach.

Cytosolic sample fractions were analyzed by two-dimensional gel electrophoresis and matrix-assisted laser desorption/ionization time-of-flight mass spectrometry with peptide mass fingerprinting for protein identification. All samples were run in triplicate. The two-dimensional gel images resolved at least 2000 protein spots (Figure 3). We identified 104 protein spots, which were at least 1.5-fold differentially regulated between FTC versus NT and FTC versus FA. A consistent expression pattern ( $\geq 5$ of $10 \mathrm{FTC}$ versus FA/NT and $\geq 1$ - to 5 -fold difference in spot quantity; $P<$.05) was detected for 18 proteins, which by PCA could be grouped into three distinct expression profiles for FTC, FA, and NT. Twelve proteins were up-regulated in FTC compared with NT, 12 proteins were differentially regulated between FTC and FA, and six proteins were 

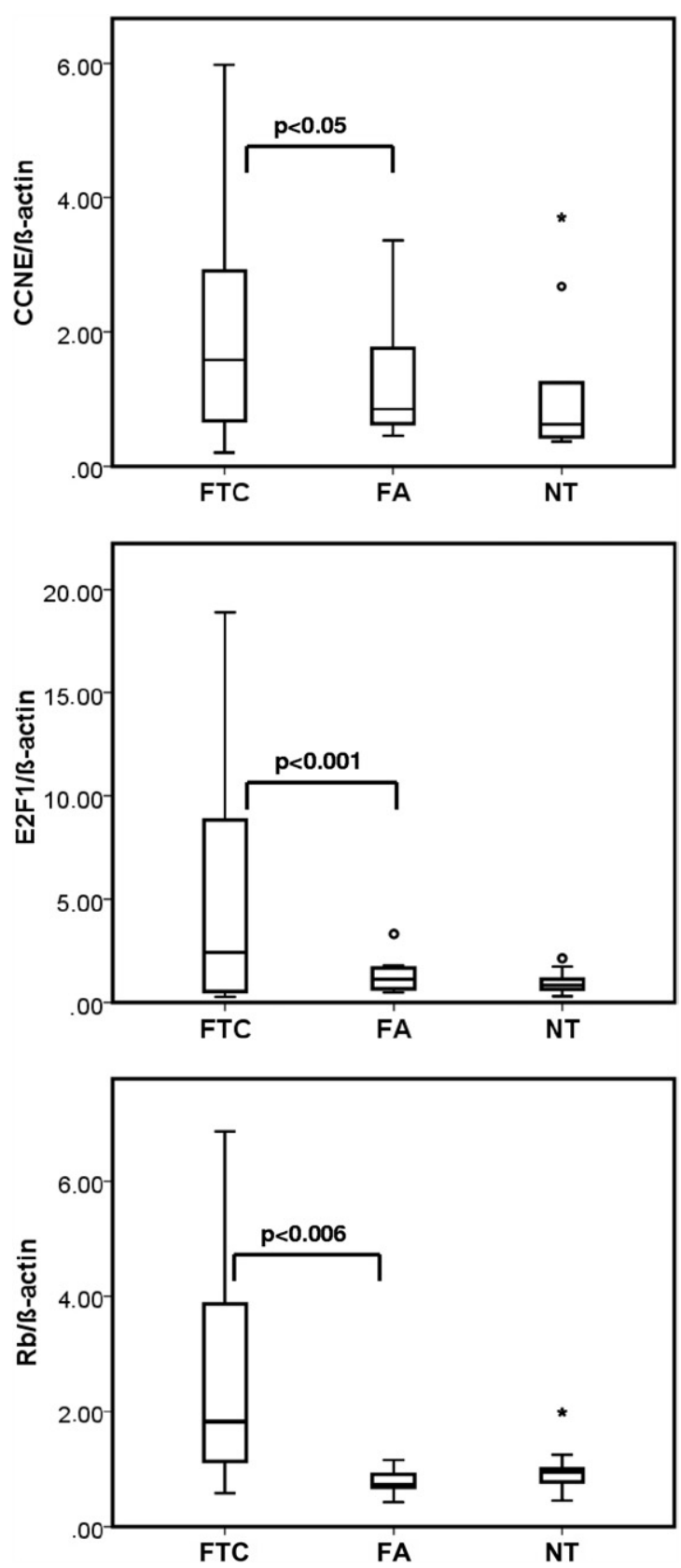

Figure 2. Increased mRNA expression of S-phase promoting oncogenes in FTC compared with FA and NT. FTCs display a significantly higher mRNA expression of the S-phase promoting oncogenes cyclin $\mathrm{E}(P<0.05), \mathrm{RB}$ $(P<0.006)$, and E2F1 $(P<0.001)$ compared with FA.

found to be up-regulated in FTC compared with both FA and NT (Table 1). Subsequently, the protein spots were analyzed by mass spectrometry.

Validation of changes in protein expression was performed by Western blotting or immunohistochemistry for three proteins that were differentially expressed in FTC compared with FA and/or NT tissues. The translationally controlled tumor protein (TCTP) was overexpressed in FTC compared with FA (1.5; $P<0.02$; Table 1$)$. TCTP is a growth-regulating protein implicated in the TSC1-TSC2mTOR pathway ${ }^{21}$ and protects cells from apoptotic cell death by antagonizing bax function. ${ }^{22,23}$ In addition,
TCTP has been suggested as a predictive marker for colon adenocarcinoma progression and tumor metastasis. ${ }^{24}$ The increased expression of TCTP in FTC versus FA was confirmed by Western blot analysis (Figure 4). Furthermore, the protein DJ-1 was significantly up-regulated in FTC compared with ST (2.5-fold; $P<0.02$; Table 1). Up-regulation of $D J-1$ has previously been shown in benign CTNs compared with corresponding surrounding tissues. ${ }^{18}$ DJ-1 (PARK7) is a protein that plays a dual role in cellular biology because a loss or gain of its function drives abnormal cellular responses, leading either to cell death (in neurodegenerative disease) or cell survival (in cancer). Subsequent immunohistochemistry confirmed the observed up-regulation of DJ-1 in FTC compared with NT (Figure 5A). Finally, I2PP2A (SET) was overexpressed in FTC compared with both ST and FA (2.2 and 1.7, respectively; for both $P<0.05$; Table 1 ). SET is an inhibitor of the PP2A, which regulates cell proliferation, survival, and differentiation. ${ }^{25}$ The overexpression of I2PP2A in FTC versus FA and NT was confirmed by immunohistochemistry (Figure 5B).

\section{Discussion}

The approach of this work was to characterize clinical samples of FA, FTC, and NT tissues based on i) the occurrence of oncogenic activation of the RAS and PI3KCA genes and PAX/PPAR $\gamma$ fusion genes, ii) the activation of natural tumorigenesis barriers, and iii) the differential protein expression with the working hypothesis that these three different viewpoints on follicular thyroid tumorigenesis might help to argue for or against a progressive development of FA to FTC.

Because it is known that most CTNs are monoclonal, ${ }^{26}$ we screened our sample set of FTC, FA, and NT for the most prevalent oncogenes found in follicular thyroid tumors (N-, H-, K-RAS, and PI3KCA mutations and PAX8/

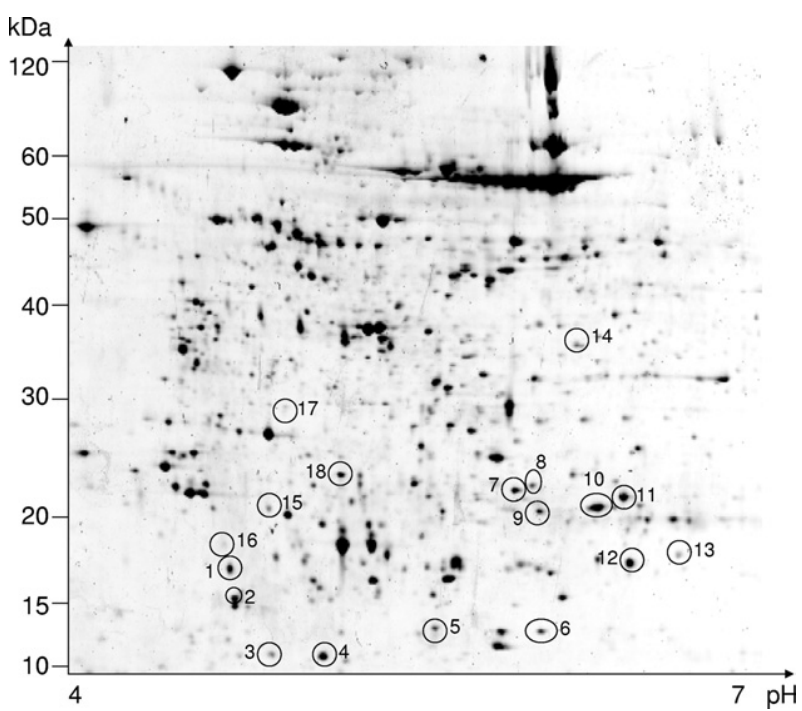

Figure 3. Changes in protein expression between FTC compared with FA and NT. Two-dimensional image of the master gel with $200 \mu \mathrm{g}$ of protein separated in $24-\mathrm{cm}, \mathrm{pH} 4$ to 7 , nonlinear IPG strips. Circled spots were identified by mass spectrometry and are listed in Table 1 . 
Table 1. Differentially Expressed Proteins in FTC Compared with NT and/or FA

\begin{tabular}{|c|c|c|c|c|c|c|c|}
\hline $\begin{array}{l}\text { Spot } \\
\text { no. }\end{array}$ & Protein identified & $\begin{array}{l}\text { SwissProt } \\
\text { accession no. }\end{array}$ & $\begin{array}{l}\text { Mascot } \\
\text { score }^{\star}\end{array}$ & $\begin{array}{l}\text { Peptides } \\
\text { matched }^{\dagger}\end{array}$ & $\mathrm{pl} / \mathrm{Mw}$ & $\mathrm{FTC} / \mathrm{NT}^{\ddagger}$ & $\mathrm{FTC} / \mathrm{FA}^{\ddagger}$ \\
\hline 1 & Protein SET (I2PP2A) & Q01105 & 95 & $14 / 31$ & $4.1 / 32.2$ & 2.2 & 1.7 \\
\hline 2 & Thioredoxin & P10599 & 186 & $10 / 11$ & $4.8 / 11.7$ & 1.5 & 1.5 \\
\hline 3 & Amyloid- $\beta$ A4 protein & P05067 & 311 & $21 / 74$ & $4.4 / 16.7$ & 2.3 & 1.5 \\
\hline 4 & Protein S100-A6 & P06703 & 123 & $5 / 12$ & $5.3 / 10.1$ & 2.5 & 1.6 \\
\hline 5 & Cathepsin B precursor & P07858 & 147 & $11 / 25$ & $5.8 / 37.8$ & 3.5 & 1.5 \\
\hline 6 & Nucleoside diphosphate kinase A & P15531 & 287 & $5 / 15$ & $5.8 / 17.1$ & 2.2 & 1.7 \\
\hline 7 & Proteasome activator complex subunit 1 & Q06323 & 273 & $20 / 38$ & $5.7 / 28.8$ & 1.7 & ND \\
\hline 8 & 6-Phosphogluconolactonase & 095336 & 350 & $17 / 21$ & $5.7 / 25.5$ & 2.5 & ND \\
\hline 9 & Heat shock protein $\beta$-1 (HSPB1) & P04792 & 327 & $16 / 22$ & $5.9 / 22.8$ & 1.8 & ND \\
\hline 10 & $\begin{array}{l}\text { 3,2-Trans-enoyl-CoA isomerase, } \\
\text { mitochondrial precursor }\end{array}$ & P42126 & 164 & $12 / 33$ & $8.8 / 32.8$ & 2.3 & ND \\
\hline 11 & Protein DJ-1 & Q99497 & 340 & $20 / 23$ & $6.3 / 29.8$ & 2.5 & ND \\
\hline 12 & Peroxiredoxin 6 & P30041 & 513 & $22 / 30$ & $6.0 / 25.3$ & ND & -1.5 \\
\hline 13 & Macrophage-capping protein & P40121 & 320 & $8 / 36$ & $5.8 / 38.5$ & ND & -2.7 \\
\hline 14 & Calpain small subunit 1 & P04632 & 390 & $19 / 21$ & $5.0 / 28.3$ & ND & -2.3 \\
\hline 15 & TCTP (p23) & P13693 & 196 & $13 / 18$ & $4.8 / 19.6$ & ND & 1.5 \\
\hline 16 & Thioredoxin-like protein 1 & О43396 & 40 & $11 / 28$ & $4.8 / 32.2$ & ND & -1.7 \\
\hline 17 & Chloride intracellular channel protein 1 & О00299 & 181 & $12 / 27$ & $5.0 / 26.9$ & ND & -1.9 \\
\hline
\end{tabular}

${ }^{*}$ Mascot score describes the significance of the search result from the search engine Mascot based on ions score, which is $10 \times \log (P)$, where $P$ is the probability that the observed match is a random event.

tNumber of matched peptides based on the peptide ion score $(P<0.05)$.

${ }^{\ddagger}$ Average ratio of differentially expressed proteins $(P<0.05)$ as calculated using triplicate gels.

$N D$, ratios that did not fulfill the selection criteria of \pm 1.5 -fold difference in protein expression and $P<0.05$.

PPAR $\gamma$ rearrangements) but did not find any of those alterations in our tissue samples. Compared with the published literature, this finding seems surprising but may be partially related to the small sample size. A low prevalence of RAS mutations has previously been reported by Krohn et al ${ }^{27}$ in benign CTNs, including FA. Furthermore, in a previous study we did not find PAX8/PPAR $\gamma$ rearrangements in an independent cohort of FTC. ${ }^{12}$ In addition, the absence of PI3KCA mutations in exon 9 and exon 20 , in which $80 \%$ of the PIK3CA mutations have been detected in different tumor types, ${ }^{28,29}$ does not preclude other oncogenic events within the PI3K cascade in the follicular thyroid tumors.
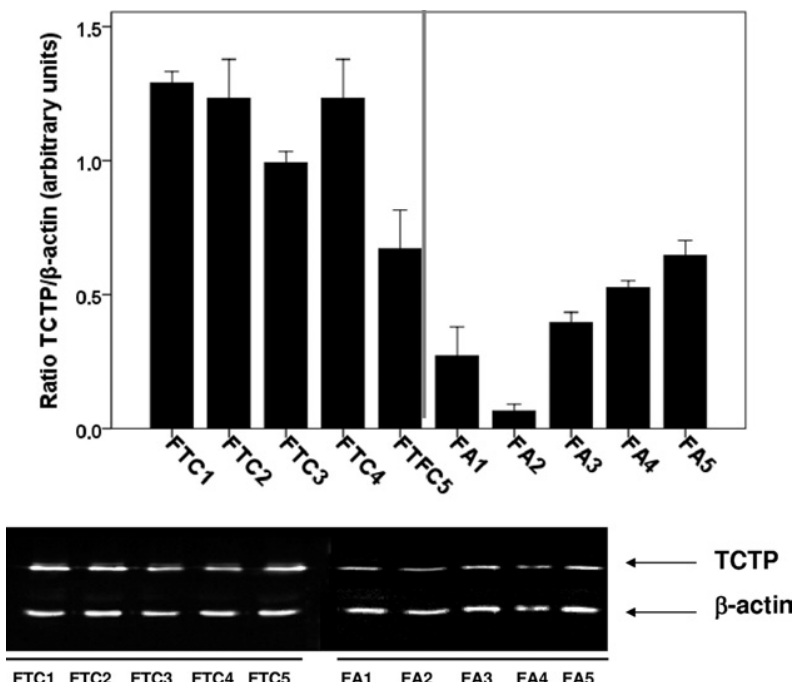

Figure 4. Western blot analysis confirming the up-regulation of TCTP in FTC compared with FA. Panel graphs correspond to the quantification of protein expression by Western blot. The data are presented as ratios corresponding to TCTP signals normalized to $\beta$-actin signals.
Previously, we have reported the increased formation of 8-oxo-guanidine DNA adducts in benign CTNs, which together with the increased proliferation rate might provide the basis for thyroid transformation. Recent studies have highlighted the function of the DDR network as a kind of tumor barrier, which slows or inhibits the neoplastic process. ${ }^{4,6,7}$ The DDR is of high biological significance in maintaining the genomic integrity in the face of genotoxic insults, such as reactive oxygen species. When cells encounter damage, the DDR is activated, which either delays cell-cycle progression to allow DNA repair or eliminates genetically altered cells from the proliferative pool. It is proposed that the DDR machinery acts as an anticancer barrier, protecting cells against the progression of tumors from their early stages into malignant invasive lesions. ${ }^{19}$ In a seminal paper, Bartkova et al ${ }^{4}$ demonstrated that several human tumors (but not normal tissue) express markers of an activated DDR, including ATM, Chk2, phosphorylated $\mathrm{H} 2 \mathrm{AX}$, and $\mathrm{p53}$, in their very early premalignant stages. Tort et $\mathrm{al}^{30}$ recently showed in human colon adenomas that high-risk grade III adenomas show multiple markers of DDR activation, whereas low-grade adenomas (grades I and II) lack detectable markers of activated DDR. Therefore, we next investigated the activation of the DDR in FA with adjacent NT and FTC. We observed the complete lack of checkpoint kinase Chk2 activation in FA and NT as opposed to a heterogeneous positive phosphorylated Chk2 staining in FTC. The same observation applied to $\gamma \mathrm{H} 2 \mathrm{AX}$ : FTC displayed a positive staining in contrast to absent staining in FA and ST (Figure 1). Thus, we observed a constitutive activation of the DDR in FTCs but not in FAs and NT tissue. In view of the absence of typical oncogenic mutations in our tumor cohort, we analyzed the mRNA expression of S-phase promoting oncogenes (cyclin E, $\mathrm{E} 2 \mathrm{~F} 1$, and $\mathrm{Rb}$ ) because their deregulated expression has 
A

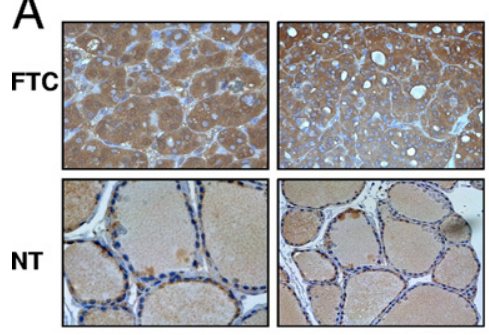

Negative control

Positive control
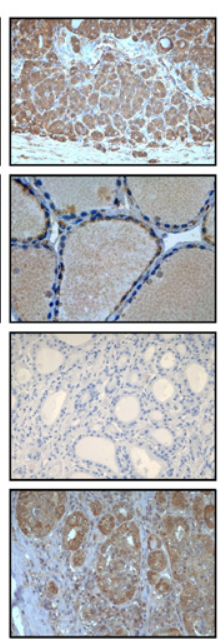

B

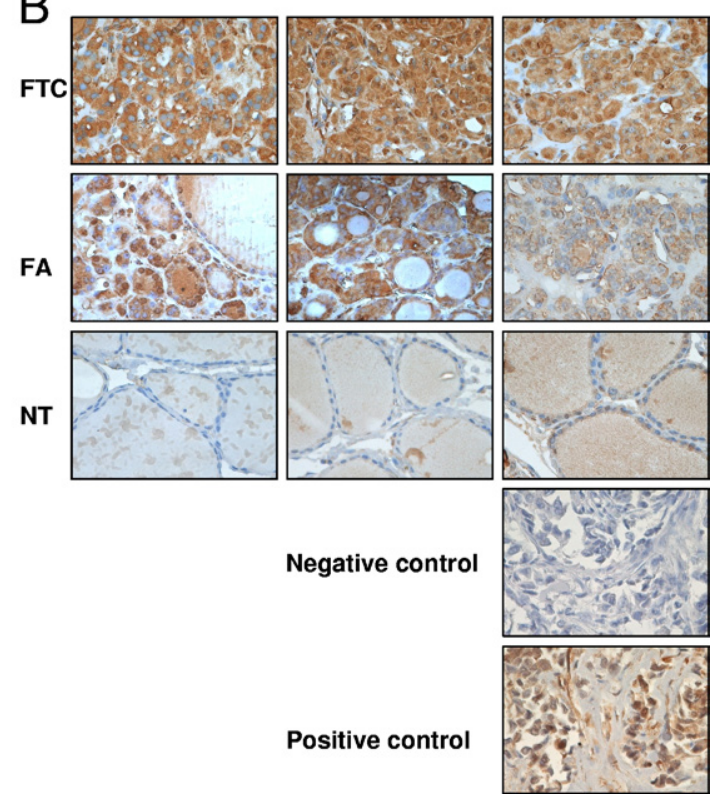

Figure 5. Immunohistochemistry confirms the differential regulation of DJ-1 and SET. A: DJ-1 is up-regulated in FTC compared with NT. Shown are representative images of 14 FTCs and 10 NTs. Original magnification, $\times 400$. B: I2PP2A is up-regulated in FTC compared with FA and NT. Shown are representative images of 18 FTCs and 14 FAs. Original magnification, $\times 400$.

been reported to represent a common finding in carcinomas and has been linked to increased replicative stress, causing genomic instability. ${ }^{31,32}$ As shown in Figure 2, the mRNA expression of all analyzed oncogenes was significantly increased in FTC compared with FA and NT. Taken together, we observed the constitutive activation of DNA damage checkpoints exclusively in FTC with a combined overexpression of S-phase promoting cell-cycle kinases cyclin E, E2F1, and Rb1. Because it is hypothesized that among the early lesions of the same tissue the DDR barrier becomes only alarmed in those tumors that bear a higher risk of malignant progression, ${ }^{4,19}$ these data could suggest that FAs evolve distinctly from FTCs.

In parallel, we were interested in dissecting the changes in protein expression occurring in FTC compared with FA or NT. Using PCA, three clusters of expression emerged: pattern $A$, proteins with similar changes in expression in FTC and FA compared with NT; pattern $\mathrm{B}$, proteins with distinct expression in FTC versus FA; and pattern $\mathrm{C}$, proteins with similar expression in FA and NT compared with FTC (Figure 3 and Table 1). These findings argue for a more distinct specific protein expression pattern in FTC compared with the condition of FA and NT tissue.

Among the identified proteins, we found three proteins that are novel in the context of follicular thyroid carcinogenesis. We detected the increased abundance of SET (I2PP2A) in FTC compared with FA and NT (ratio of 2.2 and 1.7, respectively). SET is an inhibitor of PP2A, ${ }^{33}$ a tumor suppressor with functions in cell proliferation, survival, and differentiation. ${ }^{34}$ The loss of PP2A has been associated with cell transformation. ${ }^{35}$ Recently, PP2A was identified as a AKT phosphatase, which binds and dephosphorylates AKT in an agonist-dependent manner. ${ }^{36}$ Interestingly, besides PI3KCA and AKT mutations and loss or inactivation of PTEN, the overexpression and activation of AKT are hallmarks of the deregulation of the PI3K pathway in FTCs. ${ }^{37}$ In addition, in a thyroid-specific in vitro model it was demonstrated by Hong et $\mathrm{al}^{38}$ that PP2A is also implicated in the mitogenic actions of cyclic AMP. Interestingly, in contrast to FA, we observed a strong nuclear accumulation of SET in FTC. It has been reported before that in vitro SET increased the transcriptional activity of C-Jun and AP-1. ${ }^{39}$ Finally, the hypothesis of a functionally inactivated PP2A due to the inhibitory activity of the SET protein in FTC is interesting: an increased expression of the PP2A inhibitor SET in FTC would act on three sites: i) the decreased de-phosphorylation of the AKT-kinase itself; ii) the loss of PP2A's effect on cyclic AMP-mediated AKT-dephosphorylation, which could propel thyrotropin-mediated mitogenesis; and iii) the induction of transcriptional activity of c-Jun and AP-1. Even though this hypothesis is currently speculative and yet not proven, the idea of an impaired kinase/ phosphatase network as a relevant pathomechanism in FTC is tempting.

Another protein we have identified using the proteomic approach is TCTP, which was found increased in FTC compared with FA (ratio: $1.5 ; P<0.001$ ). TCTP, a microtubule-stabilizing cytoplasmic protein, is a central player in key cellular processes (eg, cell growth, cell cycle control, malignant transformation, and the regulation of the stress and apoptotic responses). TCTP has been suggested to function as an antiapoptotic protein in cultured cells. Overexpression of TCTP resulted in inhibition of etoposide-induced apoptosis, ${ }^{22}$ whereas small interfering RNA knockdown led to increased apoptosis. ${ }^{40}$

Finally, we identified the protein DJ-1 as overexpressed in FTC compared with NT (2.5-fold, $P<0.001)$. DJ-1 has been identified as a novel oncogenic protein in 
transformed NIH3T3 cells, operating in cooperation with $\mathrm{H}$-RAS. ${ }^{41}$ Moreover, there is evidence that DJ-1 is an antioxidative protein that is induced by oxidative stress. ${ }^{42}$ The knockdown of DJ-1 expression with short interfering RNA results in susceptibility to oxidative stress. ${ }^{43}$

In summary, using different pathophysiologic and methodologic approaches to the condition of follicular thyroid tumors, we found two separate expression pattern on the proteomic approach with proteins expressed common in FA and FTC and more distinct in FTC versus FA and NT. This finding was in line with the finding of DNA damage checkpoint activation and evidence for genomic instability in FTC but not in FA. Following the reasoning of Bartkova et al and other investigators, ${ }^{4,5,30}$ these data suggest that FAs evolve distinctly from FTCs and that efforts for a molecular discrimination of these entities may benefit patients.

\section{Acknowledgments}

We thank Monika Gutknecht and Beate Jeßnitzer for excellent technical help.

\section{References}

1. Al Ghuzlan A, Caillou B, Schlumberger M: Galectin-3 for indeterminate thyroid cytology. Lancet Oncol 2008, 9:508-510

2. Bartolazzi A, Gasbarri A, Papotti M, Bussolati G, Lucante T, Khan A, Inohara $\mathrm{H}$, Marandino F, Orlandi F, Nardi F, Vecchione A, Tecce R, Larsson O: Application of an immunodiagnostic method for improving preoperative diagnosis of nodular thyroid lesions. Lancet 2001, 357: $1644-1650$

3. Bartolazzi A, Orlandi F, Saggiorato E, Volante M, Arecco F, Rossetto R, Palestini N, Ghigo E, Papotti M, Bussolati G, Martegani MP, Pantellini F, Carpi A, Giovagnoli MR, Monti S, Toscano V, Sciacchitano S, Pennelli GM, Mian C, Pelizzo MR, Rugge M, Troncone G, Palombini L, Chiappetta G, Botti G, Vecchione A, Bellocco R: Galectin-3-expression analysis in the surgical selection of follicular thyroid nodules with indeterminate fine-needle aspiration cytology: a prospective multicentre study. Lancet Oncol 2008, 9:543-549

4. Bartkova J, Horejsi Z, Koed K, Kramer A, Tort F, Zieger K, Guldberg P, Sehested M, Nesland JM, Lukas C, Orntoft T, Lukas J, Bartek J: DNA damage response as a candidate anti-cancer barrier in early human tumorigenesis. Nature 2005, 434:864-870

5. Gorgoulis VG, Vassiliou LV, Karakaidos P, Zacharatos P, Kotsinas A, Liloglou T, Venere M, DiTullio RA, Jr., Kastrinakis NG, Levy B, Kletsas D, Yoneta A, Herlyn M, Kittas C, Halazonetis TD: Activation of the DNA damage checkpoint and genomic instability in human precancerous lesions. Nature 2005, 434:907-913

6. Halazonetis TD, Gorgoulis VG, Bartek J: An oncogene-induced DNA damage model for cancer development. Science 2008, 319:1352-1355

7. Reddy JP, Peddibhotla S, Bu W, Zhao J, Haricharan S, Du YC, Podsypanina K, Rosen JM, Donehower LA, Li Y: Defining the ATMmediated barrier to tumorigenesis in somatic mammary cells following ErbB2 activation. Proc Natl Acad Sci U S A 2010, 107:3728-3733

8. Schmid KW: Molecular pathology of thyroid tumors [in French]. Pathologe 2010, 31(Suppl 2):229-233

9. Krause K, Eszlinger M, Gimm O, Karger S, Engelhardt C, Dralle H, Fuhrer D: TFF3-based candidate gene discrimination of benign and malignant thyroid tumors in a region with borderline iodine deficiency. J Clin Endocrinol Metab 2008, 93:1390-1393

10. Vasko V, Ferrand M, Di Cristofaro J, Carayon P, Henry JF, De Micco C: Specific pattern of RAS oncogene mutations in follicular thyroid tumors. J Clin Endocrinol Metab 2003, 88:2745-2752

11. Garcia-Rostan G, Costa AM, Pereira-Castro I, Salvatore G, Hernandez R, Hermsem MJ, Herrero A, Fusco A, Cameselle-Teijeiro J, Santoro M: Mutation of the PIK3CA gene in anaplastic thyroid cancer. Cancer Res 2005, 65:10199-10207
12. Karger S, Berger K, Eszlinger M, Tannapfel A, Dralle H, Paschke R, Fuhrer D: Evaluation of peroxisome proliferator-activated receptorgamma expression in benign and malignant thyroid pathologies. Dtsch Med Wochenschr 2005, 15:997-1003

13. Fuhrer D, Tannapfel A, Sabri O, Lamesch P, Paschke R: Two somatic $\mathrm{TSH}$ receptor mutations in a patient with toxic metastasising follicular thyroid carcinoma and non-functional lung metastases. Endocr Relat Cancer 2003, 10:591-600

14. Kroll TG, Sarraf P, Pecciarini L, Chen CJ, Mueller E, Spiegelman BM, Fletcher JA: PAX8-PPARgamma1 fusion oncogene in human thyroid carcinoma [corrected]. Science 2000, 289:1357-1360

15. Krause K, Schierhorn A, Sinz A, Wissmann JD, Beck-Sickinger AG, Paschke R, Fuhrer D: Towards the application of proteomics to human thyroid tissue. Dtsch Med Wochenschr 2006, 16:1131-1143

16. Shevchenko A, Tomas H, Havlis J, Olsen JV, Mann M: In-gel digestion for mass spectrometric characterization of proteins and proteomes. Nat Protoc 2006, 1:2856-2860

17. Sturn A, Quackenbush J, Trajanoski Z: Genesis: cluster analysis of microarray data. Bioinformatics 2002, 18:207-208

18. Krause K, Karger S, Schierhorn A, Poncin S, Many MC, Fuhrer D: Proteomic profiling of cold thyroid nodules. Endocrinology 2007, 148: 1754-1763

19. Bartek J, Bartkova J, Lukas J: DNA damage signalling guards against activated oncogenes and tumour progression. Oncogene 2007, 26: 7773-7779

20. Krause K, Jessnitzer B, Fuhrer D: Proteomics in thyroid tumor research. J Clin Endocrinol Metab 2009, 94:2717-2724

21. Hsu YC, Chern JJ, Cai Y, Liu M, Choi KW: Drosophila TCTP is essential for growth and proliferation through regulation of $\mathrm{dRheb}$ GTPase. Nature 2007, 445:785-788

22. Li F, Zhang D, Fujise K: Characterization of fortilin, a novel antiapoptotic protein. J Biol Chem 2001, 276:47542-47549

23. Susini L, Besse S, Duflaut D, Lespagnol A, Beekman C, Fiucci G, Atkinson AR, Busso D, Poussin P, Marine JC, Martinou JC, Cavarelli J, Moras D, Amson R, Telerman A: TCTP protects from apoptotic cell death by antagonizing bax function. Cell Death Differ 2008, 15:12111220

24. Ma Q, Geng Y, Xu W, Wu Y, He F, Shu W, Huang M, Du H, Li M: The role of translationally controlled tumor protein in tumor growth and metastasis of colon adenocarcinoma cells. J Proteome Res 2010, 9:40-49

25. Wang GL, lakova $P$, Wilde $M$, Awad S, Timchenko NA: Liver tumors escape negative control of proliferation via PI3K/Akt-mediated block of C/EBP alpha growth inhibitory activity. Genes Dev 2004, 18:912-925

26. Krohn K, Fuhrer D, Holzapfel HP, Paschke R: Clonal origin of toxic thyroid nodules with constitutively activating thyrotropin receptor mutations. J Clin Endocrinol Metab 1998, 83:130-134

27. Krohn K, Reske A, Ackermann F, Muller A, Paschke R: Ras mutations are rare in solitary cold and toxic thyroid nodules. Clin Endocrinol (Oxf) 2001, 55:241-248

28. Samuels Y, Wang Z, Bardelli A, Silliman N, Ptak J, Szabo S, Yan H, Gazdar A, Powell SM, Riggins GJ, Willson JK, Markowitz S, Kinzler $\mathrm{KW}$, Vogelstein B, Velculescu VE: High frequency of mutations of the PIK3CA gene in human cancers. Science 2004, 304:554

29. Campbell IG, Russell SE, Choong DY, Montgomery KG, Ciavarella ML, Hooi CS, Cristiano BE, Pearson RB, Phillips WA: Mutation of the PIK3CA gene in ovarian and breast cancer. Cancer Res 2004, 64: 7678-7681

30. Tort F, Bartkova J, Sehested M, Orntoft T, Lukas J, Bartek J: Retinoblastoma pathway defects show differential ability to activate the constitutive DNA damage response in human tumorigenesis. Cancer Res 2006, 66:10258-10263

31. Spruck CH, Won KA, Reed SI: Deregulated cyclin E induces chromosome instability. Nature 1999, 401:297-300

32. Mailand N, Falck J, Lukas C, Syljuasen RG, Welcker M, Bartek J, Lukas J: Rapid destruction of human Cdc25A in response to DNA damage. Science 2000, 288:1425-1429

33. Li M, Makkinje A, Damuni Z: The myeloid leukemia-associated protein SET is a potent inhibitor of protein phosphatase 2A. J Biol Chem 1996, 271:11059-11062

34. Perrotti D, Neviani P: ReSETting PP2A tumour suppressor activity in blast crisis and imatinib-resistant chronic myelogenous leukaemia. $\mathrm{Br} J$ Cancer 2006, 95:775-781 
35. Schonthal $\mathrm{AH}$ : Role of serine/threonine protein phosphatase $2 \mathrm{~A}$ in cancer. Cancer Lett 2001, 170:1-13

36. Gao T, Furnari F, Newton AC: PHLPP: a phosphatase that directly dephosphorylates Akt, promotes apoptosis, and suppresses tumor growth. Mol Cell 2005, 18:13-24

37. Paes JE, Ringel MD: Dysregulation of the phosphatidylinositol 3-kinase pathway in thyroid neoplasia. Endocrinol Metab Clin North Am 2008, 37:375-3ix

38. Hong K, Lou L, Gupta S, Ribeiro-Neto F, Altschuler DL: A novel Epac-Rap-PP2A signaling module controls CAMP-dependent Akt regulation. J Biol Chem 2008, 283:23129-23138

39. Al Murrani SW, Woodgett JR, Damuni Z: Expression of I2PP2A, an inhibitor of protein phosphatase 2A, induces C-Jun and AP-1 activity. Biochem J 1999, 341(pt 2):293-298
40. Tuynder M, Susini L, Prieur S, Besse S, Fiucci G, Amson R, Telerman $A$ : Biological models and genes of tumor reversion: cellular reprogramming through tpt1/TCTP and SIAH-1. Proc Natl Acad Sci U S A 2002, 99:14976-14981

41. Nagakubo D, Taira T, Kitaura H, Ikeda M, Tamai K, Iguchi-Ariga $\mathrm{SM}$, Ariga $\mathrm{H}$ : DJ-1, a novel oncogene which transforms mouse $\mathrm{NIH} 3 \mathrm{~T} 3$ cells in cooperation with ras. Biochem Biophys Res Commun 1997, 231:509-513

42. Mitsumoto A, Nakagawa Y: DJ-1 is an indicator for endogenous reactive oxygen species elicited by endotoxin. Free Radic Res 2001, 35:885-893

43. Taira T, Saito Y, Niki T, Iguchi-Ariga SM, Takahashi K, Ariga H: DJ-1 has a role in antioxidative stress to prevent cell death. EMBO Rep 2004, 5:213-218 